Supporting Information (SI) for:

\title{
Polarized Electronic Configuration in Transition Metal-Fluoride Oxide Hollow Nanoprism for Highly Efficient and Robust Water Splitting
}

HyukSu Han ${ }^{1, *}$, , Jungwook Woo ${ }^{2, \dagger}$, Yu-Rim Hong ${ }^{3}$, Yong-Chae Chung ${ }^{2, *}$, and Sungwook Mhin ${ }^{4, *}$

${ }^{1}$ Department of Materials Science and Engineering, Hongik University, Sejong-ro 2639, Sejong, Republic of Korea. *Email:hhan@hongik.ac.kr

${ }^{2}$ Division of Materials Science and Engineering, Hanyang University, 222 Wangsimni-ro, Seongdong-gu, Seoul 04763, Republic of Korea. *Email:yongchae@hanyang.ac.kr

${ }^{3}$ Korea Institute of Industrial Technology, 137-41 Gwahakdanji-ro, Gangneung-si, Gangwon 25440, Republic of Korea.

${ }^{4}$ Korea Institute of Industrial Technology, 156 Gaetbeol-ro, Yeonsu-gu, Incheon 406-840, Republic of Korea. *Email: hyeleci@kitech.re.kr 
Synthesis of Ni-Co hydroxide (NCO) precursors: All the chemicals were purchased from Sigma Aldrich and were directly used without further purification. Typically, a mixture of metal acetate tetrahydrate $(1.28 \mathrm{~g})$ with a molar ratio of $\mathrm{Ni} / \mathrm{Co}(2: 1)$ were dissolved in $200 \mathrm{ml}$ of ethanol at room temperature. The solution was then refluxed at $85^{\circ} \mathrm{C}$ for $4 \mathrm{hrs}$. The precipitate was centrifuged and rinsed with ethanol for several times. The resultant powder is subsequently dried in air at $60^{\circ} \mathrm{C}$.

Synthesis of Nickel Cobalt Boride (NCBO): Ni-Co hydroxides nanoprisms (0.08 g) were dispersed in anhydrous ethanol $(40 \mathrm{ml})$ by sonicating for $5 \mathrm{~min}$. After complete dissolution of the Ni-Co precursors, $0.1 \mathrm{~g}$ of sodium borohydride was added to the solution and further sonicating for a few minute. The resulting mixture was then transferred to a $200 \mathrm{~mL}$ Teflon ${ }^{\circledR}$ lined stainless-steel autoclave and hydrothermally reacted at $120^{\circ} \mathrm{C}$ for $1 \mathrm{~h}$. The resultant product was washed several times with ethanol and centrifuged. The collected powder was dried at $70^{\circ} \mathrm{C}$ for overnight.

Synthesis of Nickel Cobalt Fluoride-Oxide (NCFO): The prepared nickel cobalt boride was reacted with fluorine vapor (from $\mathrm{NH}_{4} \mathrm{~F}$ ) at $300-500^{\circ} \mathrm{C}$ in a chemical vapor deposition (CVD) apparatus. In $\mathrm{CVD}, \mathrm{NH}_{4} \mathrm{~F}$ was decomposed to ammonia and hydrogen fluoride at around $200^{\circ} \mathrm{C}$. Nickel cobalt boride was converted to fluoride-oxide upon reaction with hydrogen fluoride. The nickel cobalt boride powder was placed at the middle of a quartz tube, while $\mathrm{NH}_{4} \mathrm{~F}(\sim 1 \mathrm{~g})$ was placed at the upstream side of the furnace far away from the heating zone. The furnace was heated to $300-500^{\circ} \mathrm{C}$ in $\operatorname{Ar}(100 \mathrm{sccm})$ at 6.4 Torr for different time $(10,30$, and $45 \mathrm{~min})$. Ar was used as a protective gas during the reaction.

Characterizations: Scanning electron microscopy (SEM; model S4800; Hitachi) was used to 
obtain microstructural images of each sample. Transmission electron microscopy (TEM) and corresponding energy dispersive X-ray (EDX) mapping images were acquired using a Talos F200X (Thermo Fisher Scientific) microscope equipped with an EDX analyzer at $200 \mathrm{kV}$. Xray diffraction (XRD) patterns were measured using a D/MAX-2500/PC (Rigaku) diffractometer with $\mathrm{Cu}-\mathrm{K} \alpha$ radiation $(\lambda=0.15418 \mathrm{~nm})$ at $40 \mathrm{kV}$ and $100 \mathrm{~mA}$. Raman spectroscopy was performed via a dispersive laser spectrophotometer (model NRS-3100; JASCO) at room temperature with an excitation wavelength of $633 \mathrm{~nm}$. X-ray photoelectron spectroscopy (XPS) spectra were recorded for the samples using a VG ESCALAB 200i instrument (Thermo Fisher Scientific). XPS survey and high-resolution scans were conducted with pass energies of 100 and $20 \mathrm{eV}$, respectively. The specific surface area was measured by nitrogen adsorption-desorption tests (model TriStar II 3020; Micromeritics) following the Brunauer-Emmett-Teller (BET) theory.

Electrochemical characterization: The electrocatalytic activity of NCFO was tested in a basic medium (1 $\mathrm{M} \mathrm{KOH}$ aqueous solution) using a typical three-electrode system with a rotating disk electrode (RDE) and a loading amount of $0.28 \mathrm{mg} \mathrm{cm}^{-2}$. For comparison, $\mathrm{NCBO}$ and the benchmark catalyst $\mathrm{RuO}_{2}$ were also tested. Before measuring the polarization curves, continuous cyclic voltammetry $(\mathrm{CV})$ was performed until a reproducible curve was obtained. Linear sweep voltammetry (LSV) was performed at a scan rate of $5 \mathrm{mV} \mathrm{s}^{-1}$. The RDE was continuously rotated at $1,600 \mathrm{rpm}$ to remove bubbles generated during measurement. The potential values were $i R$-compensated and referenced to the reversible hydrogen electrode (RHE).

Influence of Nickel Foam (NF) as Support: A piece of nickel foam $\left(0.5 \times 1 \mathrm{~cm}^{2}\right)$ was modified with NCFO by drop casting and the water oxidation properties were examined. Firstly, NF was cleaned ultrasonically with acetone $(20 \mathrm{ml})$ and then with $3 \mathrm{M} \mathrm{HCl}$ solution $(20 \mathrm{ml})$ 
for $10 \mathrm{~min}$ in each. Then, subsequent washing was followed using water and ethanol for several times. The cleaned NF was immersed in a mixture of water and ethanol (1:1 volume ratio), and the $12 \mu \mathrm{l}$ of catalyst ink was drop-coated while the NF is wet. To attain the same loading amount $\left(0.285 \mathrm{mg} \mathrm{cm}^{-2}\right)$ as on GC RDE electrode, drop coating was repeated for three times while allowing the catalysts to be sufficiently dried within coating steps. The exact loading amount was verified by weighing using a high precision balance.

Calculation of Turn over Frequency (TOF): TOFs of the catalysts were calculated by using the following equation,

$T O F=j \times A /\left(4 \times F \times N_{s}\right)$

, where $j$ is the current density $\left(\mathrm{A} \mathrm{cm}^{-2}\right)$ at the given overpotential, $A$ is the area of the electrode $\left(\mathrm{cm}^{-2}\right), F$ is the Faraday constant $\left(96,485 \mathrm{C} \mathrm{mol}^{-1}\right)$, and $N_{s}$ is the concentration of active sites in the catalysts $\left(\mathrm{mol} \mathrm{cm} \mathrm{cm}^{-2}\right)$.[S1] To calculate $N_{s}$, cyclic voltammetry $(\mathrm{CV})$ was performed for the redox reactions at different scan rates in $1.0 \mathrm{M} \mathrm{KOH}$ electrolyte. The peak currents were plotted verses scan rates where the slope is equal to,

Slope $=n^{2} F^{2} A N_{s} / 4 R T$

, where $\mathrm{n}$ is the amount of electrons transferred (here $\mathrm{n}=1$ ), F presents Faradic constant, $\mathrm{A}$ is the surface area of the electrode, $N s$ is the surface concentration of active sites $\left(\mathrm{mol} \mathrm{cm}^{-2}\right), \mathrm{R}$ and $\mathrm{T}$ are the ideal gas constant and the absolute temperature, respectively.[S1-2]

Calculation of Faraday Efficiency (FE) during Water Oxidation: FE of ECA-CNS was measured by using a rotating ring disk electrode (RRDE). A ring potential of $0.4 \mathrm{~V}_{\mathrm{RHE}}$ was applied to detect $\mathrm{O}_{2}$ molecules generated by oxygen reduction reaction (ORR). A constant current of $0.48 \mathrm{~mA}$ was applied to the disk electrode for $\mathrm{O}_{2}$ generation, and then FE of CNSNGA was calculated using the following equation. 


$$
F E=i_{\text {ring }} /\left(i_{\text {disk }} \times N\right)
$$

where, $\mathrm{i}_{\text {disk }}, \mathrm{i}_{\text {ring }}$, and $\mathrm{N}$ denote the disk current, the ring current, and the current collection efficiency of the RRDE which is generally about 0.2 .

Calculation of Electrochemical Double Layer Capacitance $\left(\boldsymbol{C}_{d D}\right)$ : The CV test was performed in an $\mathrm{O}_{2}$-saturated $1 \mathrm{M} \mathrm{KOH}$ solution to estimate the $C_{d l}$ at non-Faradaic overpotentials. A series of CV measurements were conducted at various scan rates $(20,40,60,80,100$, and 120 $\mathrm{mV} \mathrm{s}^{-1}$ ) ranging from 1.01 to $1.11 \mathrm{~V}$ vs. RHE. The difference in current density between the anodic and cathodic sweeps $\left(\mathrm{J}_{\text {anodic }}-\mathrm{J}_{\text {cathodic }}\right)$ at $1.435 \mathrm{~V}$ vs. RHE was plotted as a function of the scan rate, where the slope was equal to twice the $\mathrm{C}_{\mathrm{dl}}$ of the catalyst.

Calculation of Electrochemical Surface Area (ECSA): The ECSAs of catalysts have been attained from their $C_{d l}$. The current generated in the non-Faradaic region is attributed to charging of double layer and shows linear relationship with the active surface area. Generally, the specific capacitance of $1 \mathrm{~cm}^{2}$ flat surface area is corresponding to $C_{\mathrm{dl}}$ value of $20-60 \mu \mathrm{F}$ $\mathrm{cm}^{-2}$ with an average value of $40 \mu \mathrm{F} \mathrm{cm}^{-2}$.[S3] Thus, the $C_{d l}$ can be converted to the ECSA as below.

$E C S A=C_{d l}$ of catalyst $\left(\mathrm{mF} \mathrm{cm} \mathrm{cm}^{-2}\right) / 0.04 \mathrm{mF} \mathrm{cm}^{-2}$

Density Functional Theory (DFT) Calculations: Simulations with the aim of predicting OER process on $\mathrm{CoNiF}_{2}$ and $\mathrm{NiF}_{2}$ were performed with first-principles DFT using the generalized gradient approximation (GGA) of Perdew, Burke, and Ernzerhof (PBE),[S4] including spin polarization. First-principles calculations were conducted using the Vienna Ab-initio Simulation Package (VASP).[S5-7]

The $\mathrm{NiF}_{2}$ and $\mathrm{CoNiF}_{2}$ models were designed by taking a $2 \times 2 \times 3 \mathrm{NiF}_{2}$ supercell and a vacuum spacing of $10 \AA$ to the normal direction. The modeled structures of $\mathrm{NiF}_{2}$ system consists of 
$24 \mathrm{Ni}$ atoms and $\mathrm{CoNiF}_{2}$ system consists of $48 \mathrm{~F}$ atoms and $17 \mathrm{Ni}$ atoms, $48 \mathrm{~F}$ atoms, and $7 \mathrm{Co}$ atoms, respectively. Slab models of the $\mathrm{NiF}_{2}$ and $\mathrm{CoNiF}_{2}$ are considered as the (100) planes, which is most stable surface among low index system of $\mathrm{NiF}_{2}$ and $\mathrm{CoNiF}_{2}$. All of selfconsistent loops were iterated until the total energy difference of the system between adjacent iterating steps became less than $1 \times 10^{-5} \mathrm{eV}$. The calculations were performed with a $1 \times 1 \times 1$ gamma-point-centered k-point sampling generated by the Monkhorst-Pack scheme for the supercell calculation. The modeled structure were fully relaxed until the Hellman-Feynman forces were in the range of $0.02 \mathrm{eV} / \AA^{-1}$. Ionic relaxation was executed using the conjugate gradient method. The electronic structure was calculated using the Gaussian-smearing method with a width of $0.05 \mathrm{eV}$. The optimized lattice parameters were found to be $\mathrm{a}=4.70 \AA$ and $\mathrm{c}=3.12 \AA$. The van der Waals interactions were taken into account through a dispersion correction as proposed by Grimme and with the Becke - Johnson damping (DFT-D3 (BJ) method)

The four electron reaction pathway for OER is considered as follows:

$$
\begin{aligned}
& 2 \mathrm{H}_{2} \mathrm{O}(l)+* \leftrightarrow \mathrm{H}_{2} \mathrm{O}+\mathrm{H}^{*}+\mathrm{H}^{+}+e^{-} \\
& \mathrm{H}_{2} \mathrm{O}(l)+* \leftrightarrow \mathrm{HO} *+H^{+}+e^{-} \\
& \mathrm{H}_{2} \mathrm{O}+\mathrm{O}^{*}+2\left(\mathrm{H}^{+}+e^{-}\right) \leftrightarrow \mathrm{HOO}^{*}+3\left(H^{+}+e^{-}\right) \\
& \mathrm{HOO}^{*}+3\left(\mathrm{H}^{+}+e^{-}\right) \leftrightarrow *+\mathrm{O}_{2}+4\left(H^{+}+e^{-}\right)
\end{aligned}
$$

where the asterisk mark indicates the substrate and the adsorbed state of molecules on the substrate. Following to the approach of Valdés et al.,[S8] the free energies of the OER intermediates was calculated as follows:

$\Delta \mathrm{G}=\Delta E^{t o t}+\Delta E^{Z P E}-T \Delta S$

where $\Delta E^{t o t}, \Delta E^{Z P E}$, and $T \Delta S$ indicates the total energy change obtained from the DFT calculations, the change in the zero-point energies, and the change in the entropy at $\mathrm{T}=298.15 \mathrm{~K}$, 
respectively. It is assumed that the hydrogen electrode in equilibrium are in equilibrium with the hydrogen in the gas phase:

$H^{+}(a q)+e^{-} \leftrightarrow \frac{1}{2} H_{2}(g)$

$\mu_{H^{+}}+\mu_{e^{-}}=\frac{1}{2} \mu_{H_{2}}$

where $\mu_{H^{+}}=\mu_{H^{+}}^{0}-k_{B} T \ln 10 \times p H, \mu_{e^{-}}=\mu_{e^{-}}^{0}-e U$ and $\mu_{H_{2}}=\mu_{H_{2}(g)}^{0}+k_{B} T \ln p_{H_{2}(g)}$.

The entropy of gas phase molecule $\left(\mathrm{H}_{2} \mathrm{O}\right.$ and $\left.\mathrm{H}_{2}\right)$ is corrected by the experimental entropy correction.[S9] Moreover, the gas phase oxygen molecule is hard to calculate accurately with DFT calculation. Therefore, using the experimental value of $2.46 \mathrm{eV}$ of standard free energy change of the water splitting reaction $\left(\mathrm{H}_{2} \mathrm{O}(l) \leftrightarrow \frac{1}{2} \mathrm{O}_{2}(g)+\mathrm{H}_{2}(g)\right)$, the free energy of oxygen molecule for gas phase is expressed as:

$G_{O_{2}}^{0}=4.92 \mathrm{eV}+2 G_{\mathrm{H}_{2} \mathrm{O}}^{0}-2 G_{\mathrm{H}_{2}}^{0}$ 

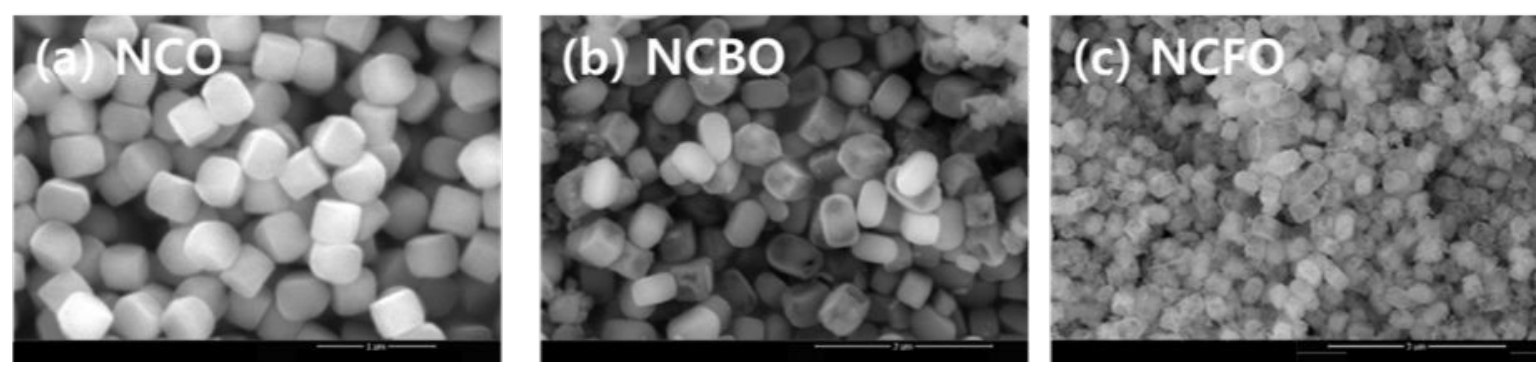

Figure S1. Scanning electron microscopy (SEM) image of (a) nickel-cobalt-hydroxide (NCO) precursors with Ni:Co molar ratio of 2:1 after(b) boronization and (c) fluorization.

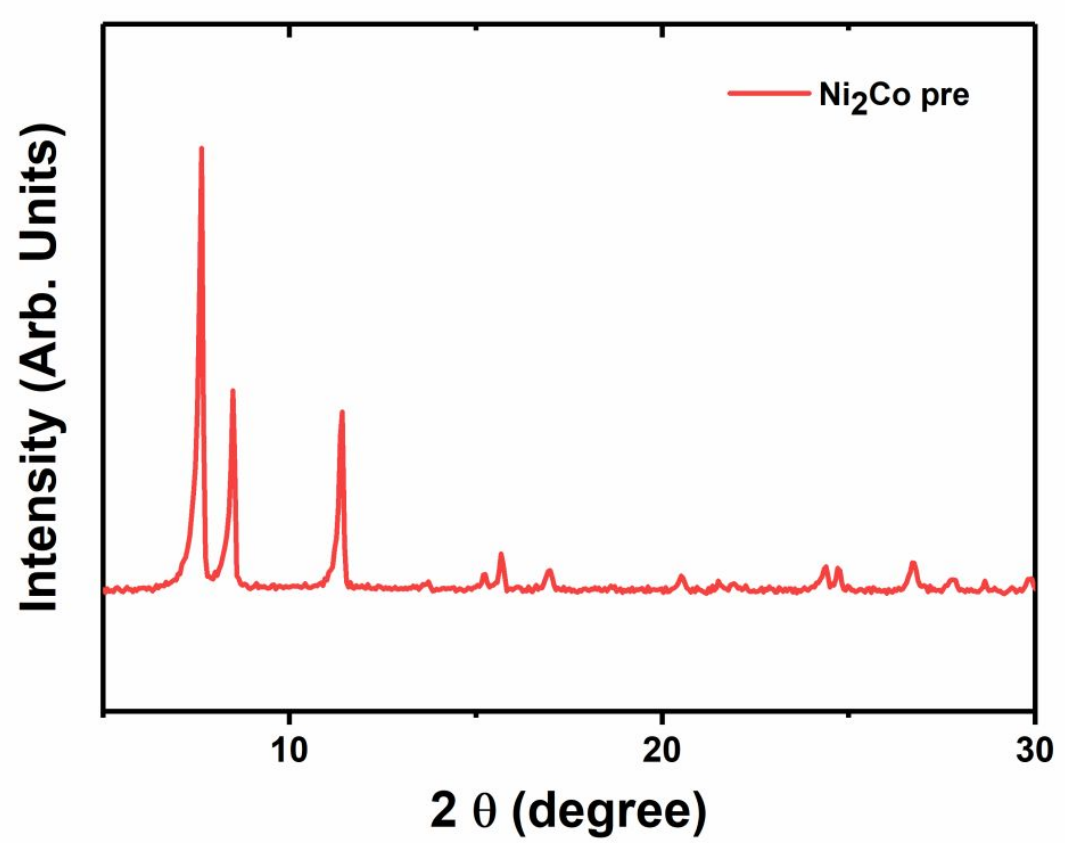

Figure S2. X-ray diffraction (XRD) patterns of NCO precursor. 


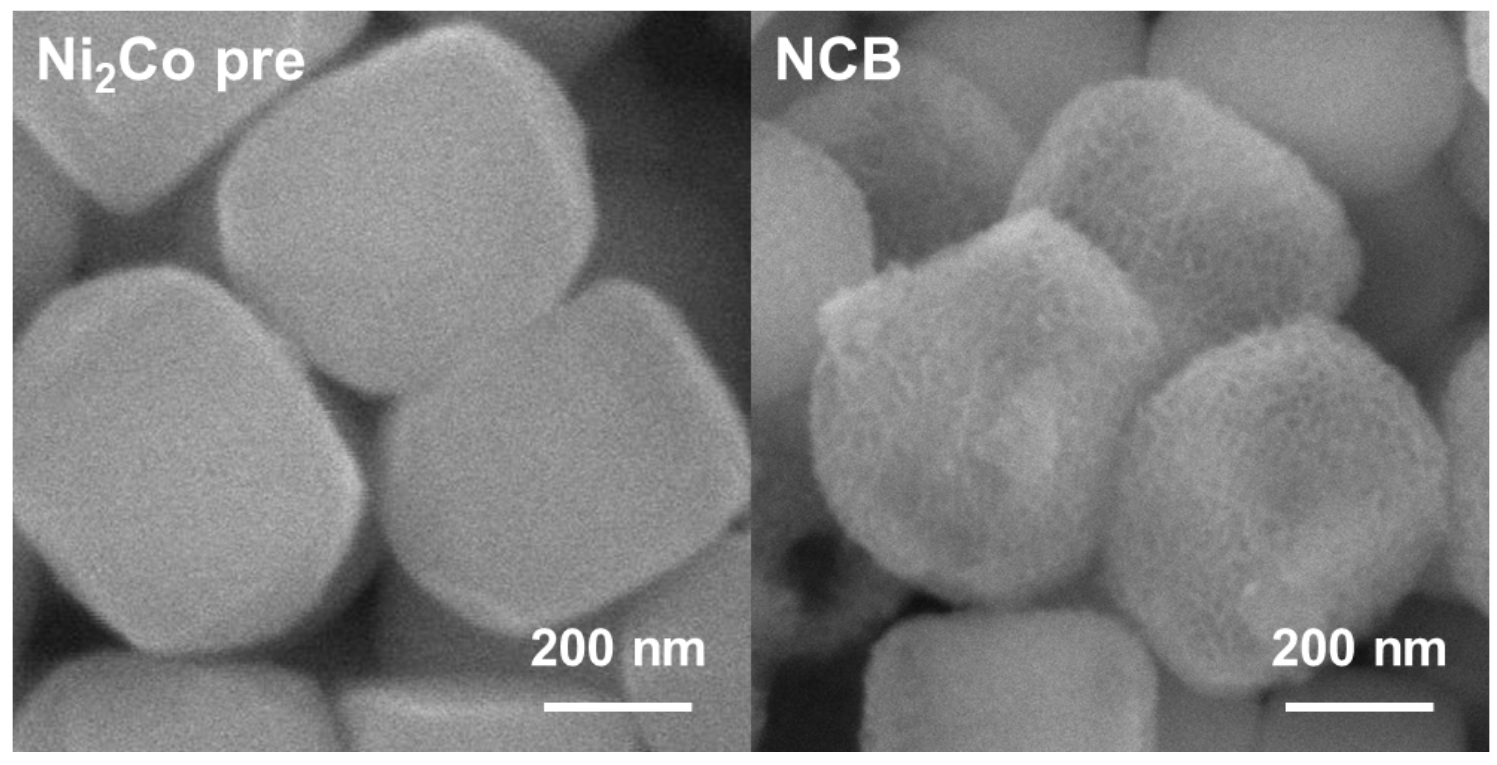

Figure S3. SEM images of a) NCO precursor and b) NCBO

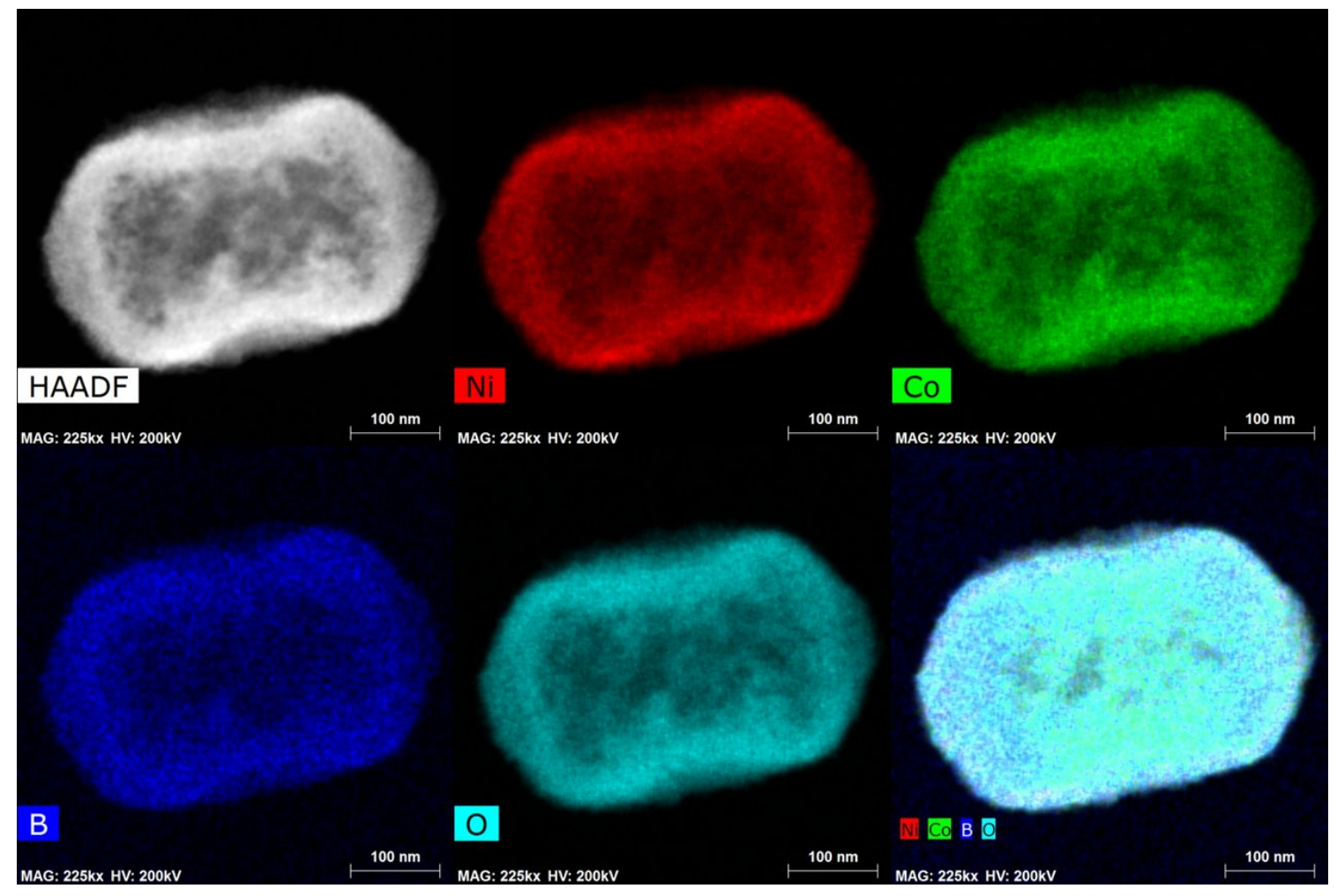

Figure S4. Elemental mapping images of NCBO (HAADF) for Ni, Co, B, O, and all. 


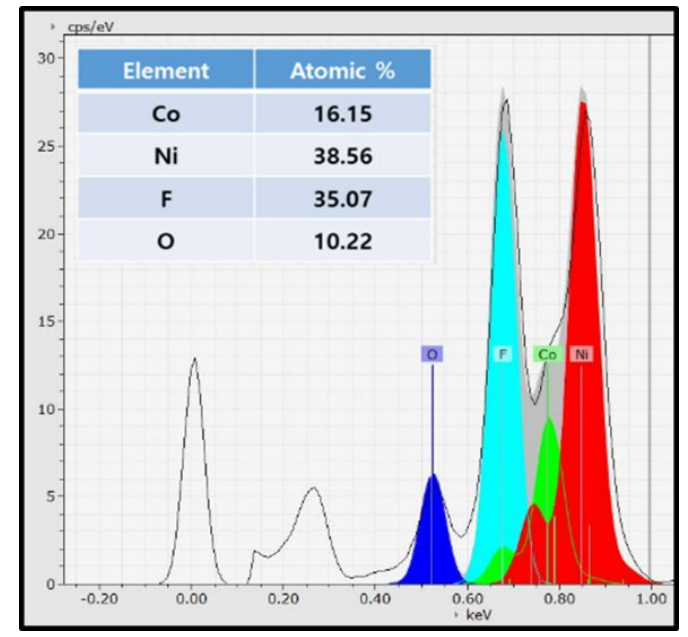

Figure S5. Quantitative analysis for mapping data of NCFO.

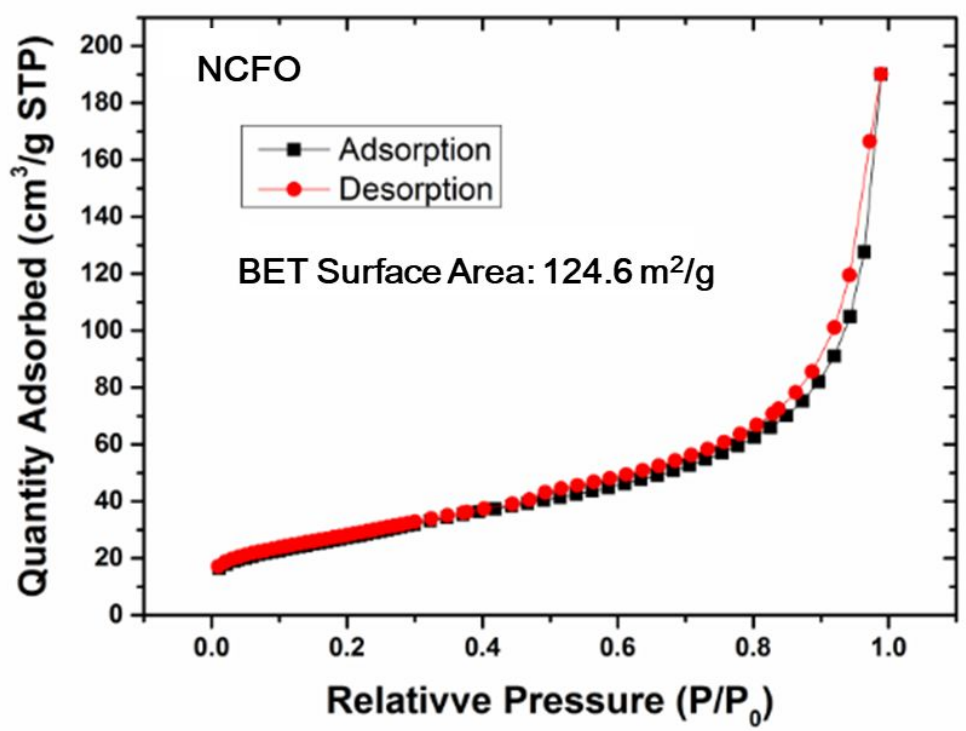

Figure S6. $\mathrm{N}_{2}$ adsorption-desorption isotherm of NCFO. 

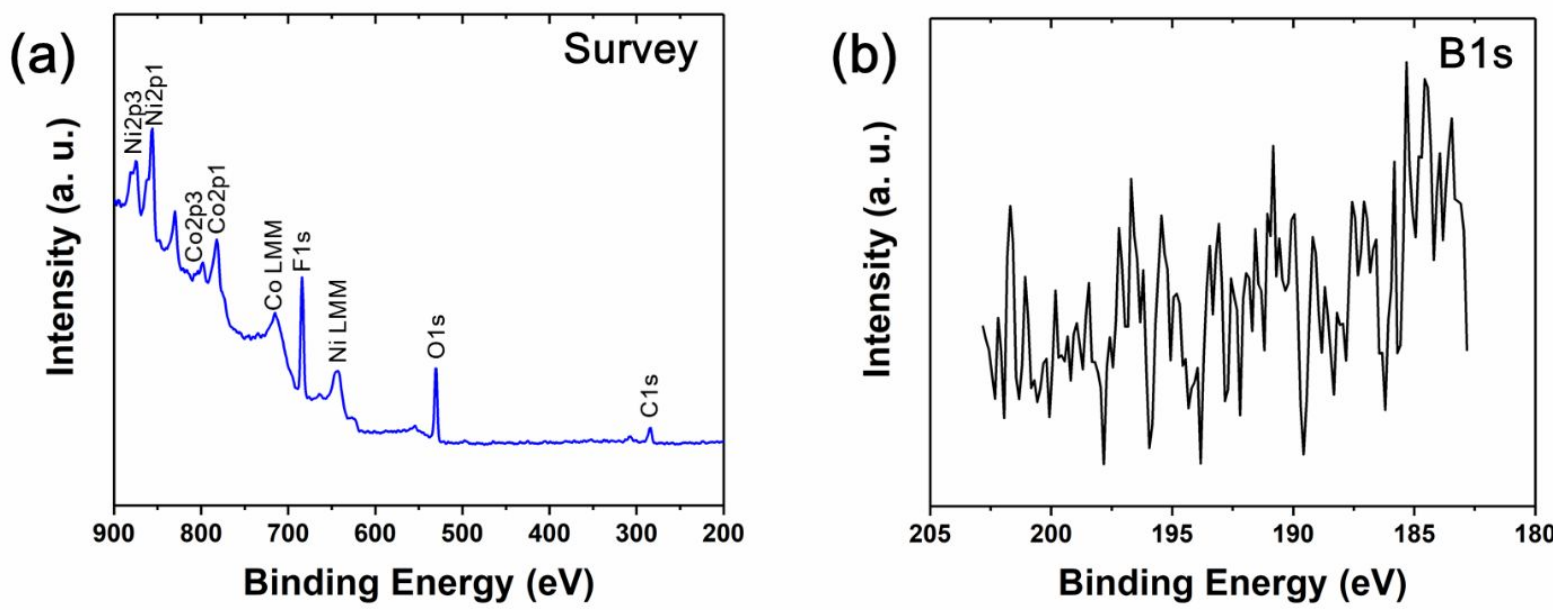

Figure S7. a) XPS survey spectra and b) high-resolution XPS spectra of B 1s for NCFO.
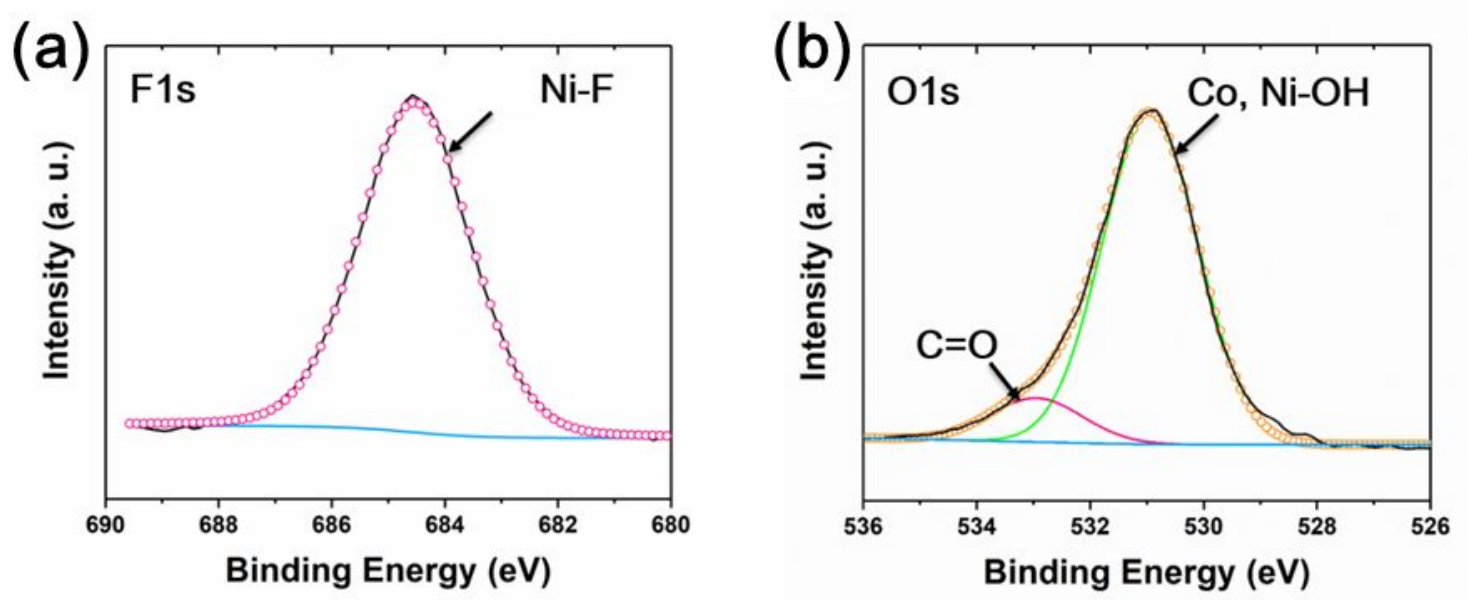

Figure S8. High-resolution XPS spectra for a) F1s and b) O1s of NCFO. 

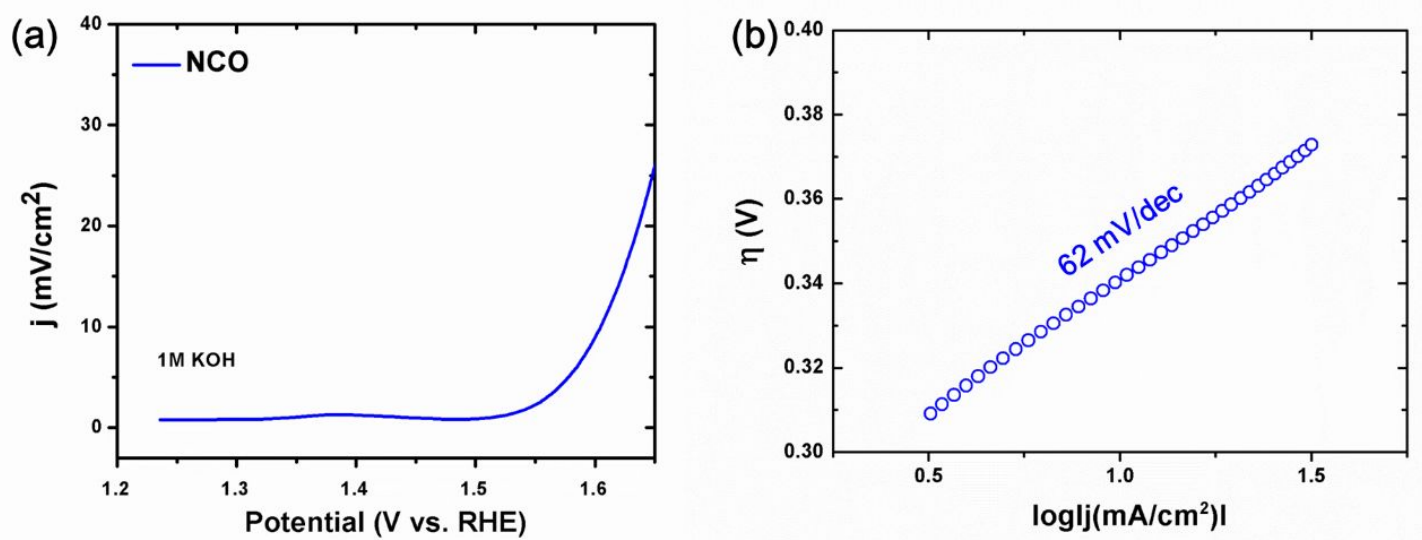

Figure S9. a) LSV polarization curves and b) Tafel plot of NCO measured in $1.0 \mathrm{M} \mathrm{KOH}$ with scan rate of $5 \mathrm{mV} \mathrm{s}^{-1}$.
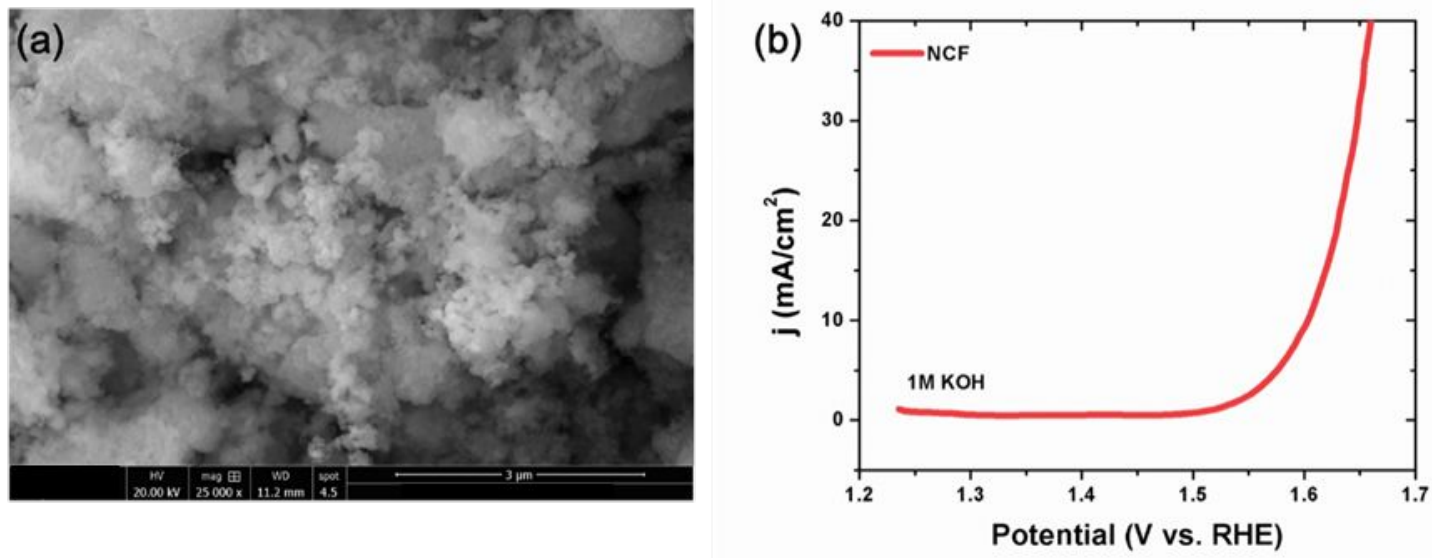

Figure S10. a) SEM image of nickel-cobalt-fluoride (NCF) and b) its LSV polarization curves measured in $1.0 \mathrm{M} \mathrm{KOH}$ with scan rate of $5 \mathrm{mV} \mathrm{s}^{-1}$.
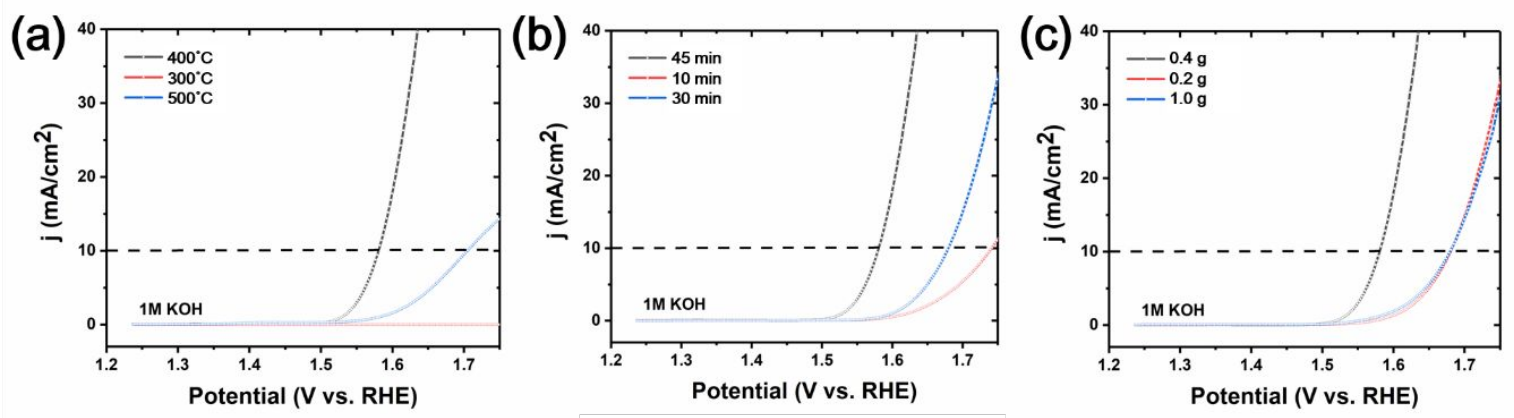

Figure S11. LSV polarization curves of NCFO synthesized at a) different temperatures, b) different times, and c) using a different amount of $\mathrm{NH}_{4} \mathrm{~F}$ (fluorine source). 


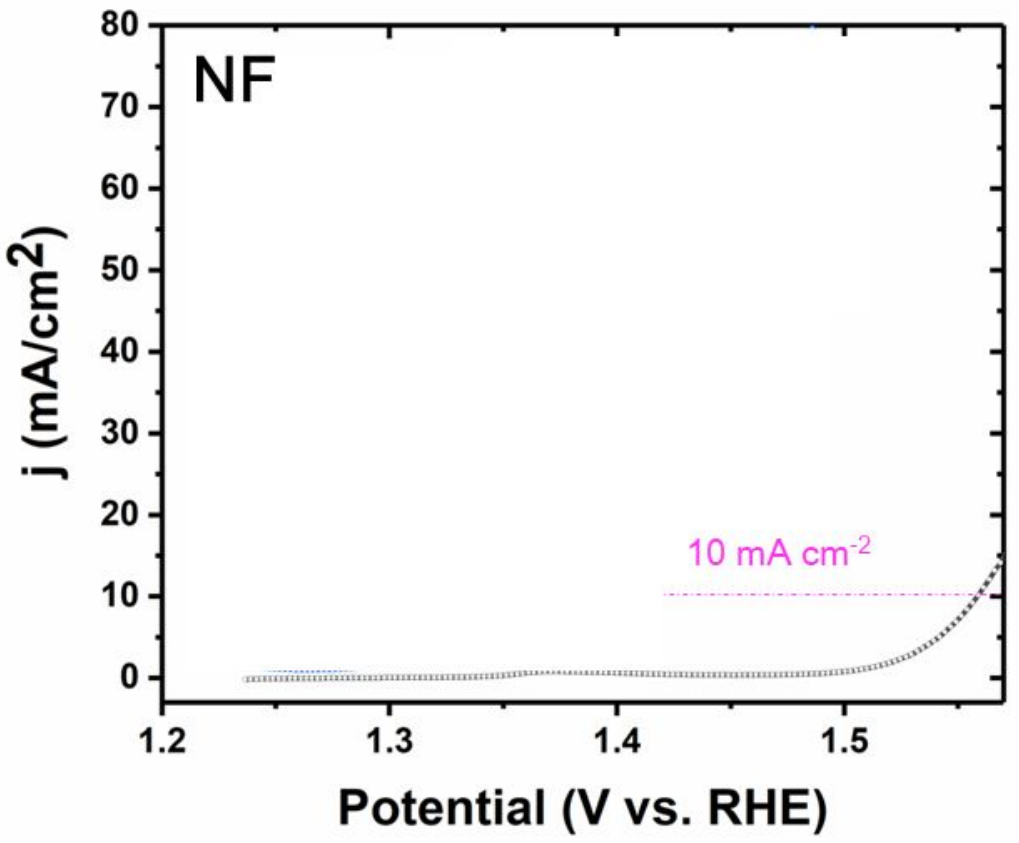

Figure S12. LSV polarization curves of bare nickel foam (NF) in $1.0 \mathrm{M} \mathrm{KOH}$. 

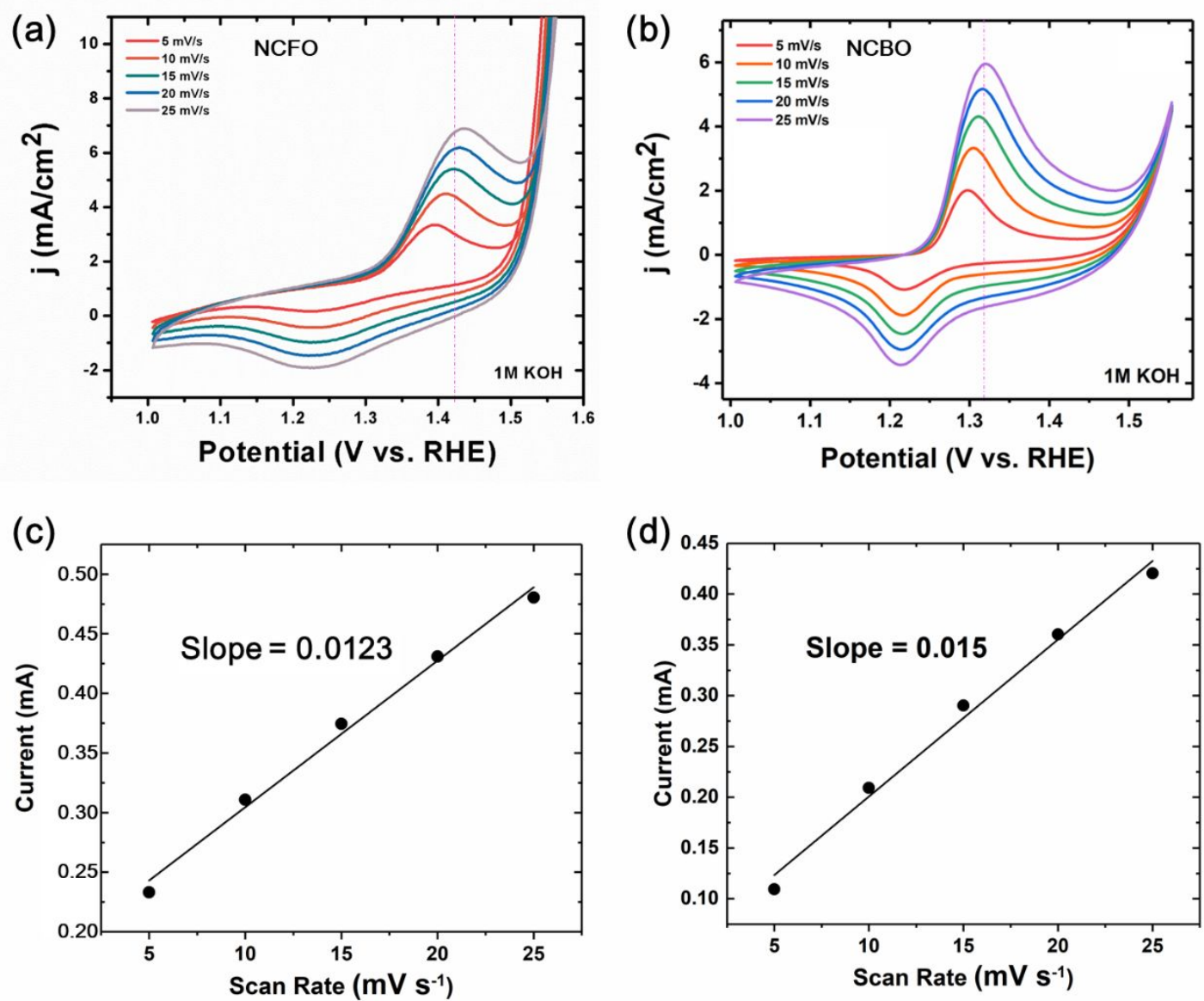

Figure S13. CVs of a) NCFO, b) NCBO at scan rates of 5, 10, 15, 20, and $25 \mathrm{mV} \mathrm{s}^{-1}$ in 1.0 $\mathrm{M} \mathrm{KOH}$. Linear relationship of the oxidation peak currents vs. scan rates for c) NCFO and d) NCBO. 

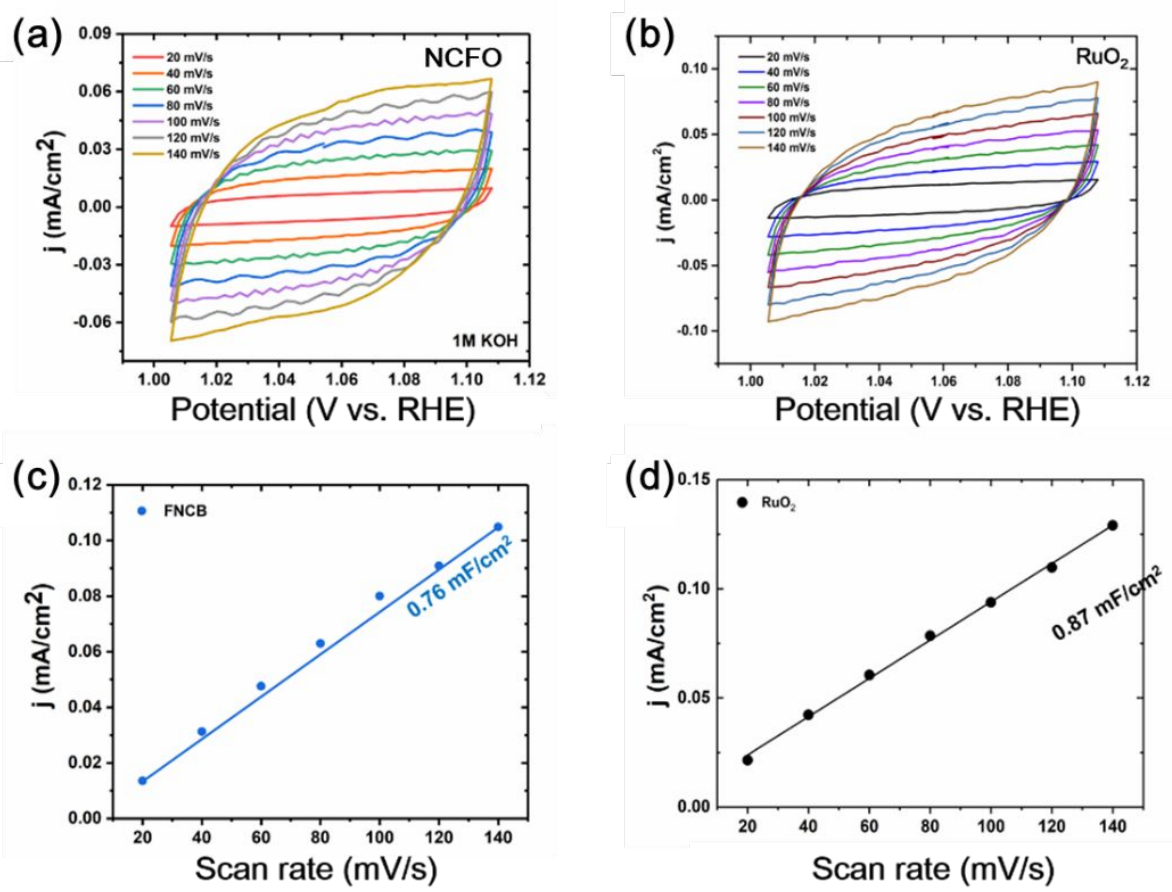

Figure S14. CVs in a capacitive current region $(1.01-1.11 \mathrm{~V}$, not $i R$-compensated) at various scan rates, 20, 40, 60, 80, 100, 120, and $140 \mathrm{~s}^{-1}$, of a) $\mathrm{NCFO}$ and b) $\mathrm{RuO}_{2}$. The current difference between the anodic and cathodic sweeps as a function of scan rate for c) NCFO and d) $\mathrm{RuO}_{2}$. The solid line is a linear fitting of the data; the slope of the fitted line was used to calculate the electrical double-layer capacitance $\left(C_{d l}\right)$.

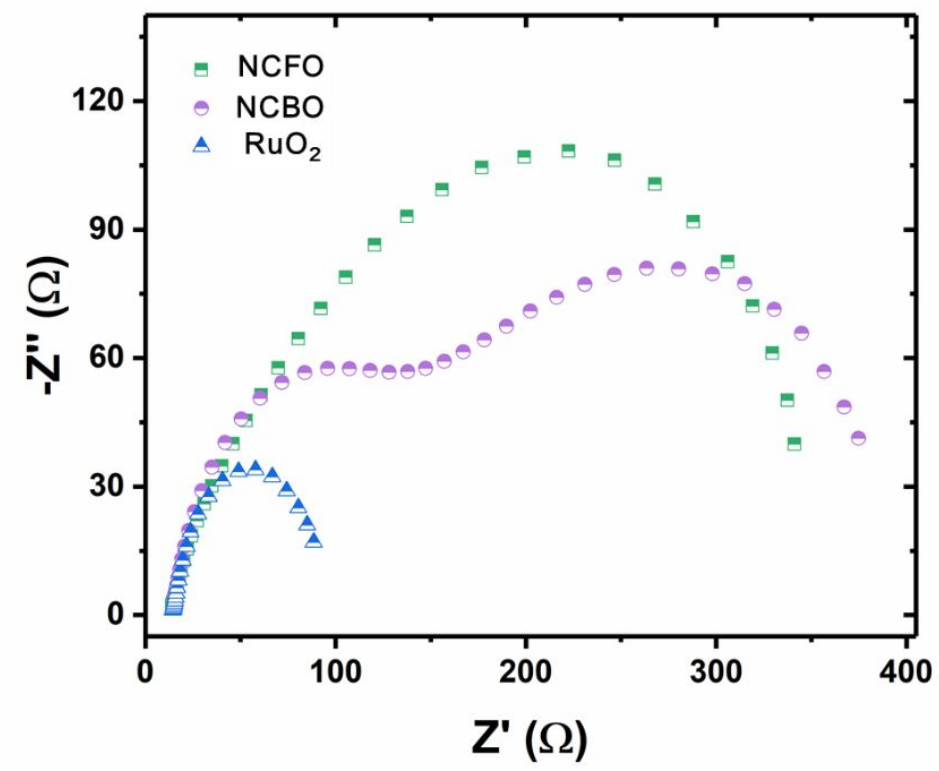

Figure S15. Nyquist plots of $\mathrm{NCFO}, \mathrm{NCBO}$, and $\mathrm{RuO}_{2}$ in a frequency range from 0.1 to 100 $\mathrm{kHz}$. A sinusoidal voltage with an amplitude of $5 \mathrm{mV}$ was applied. 


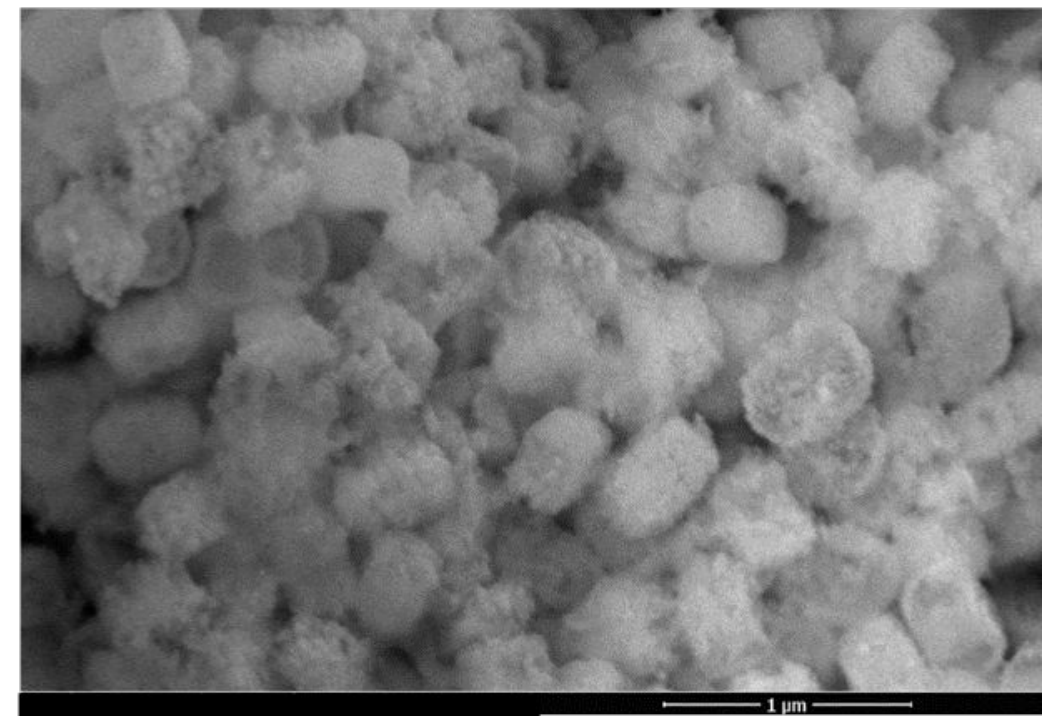

Figure S16. SEM image of NCFO after prolonged OER in 1M KOH solution.

(a)

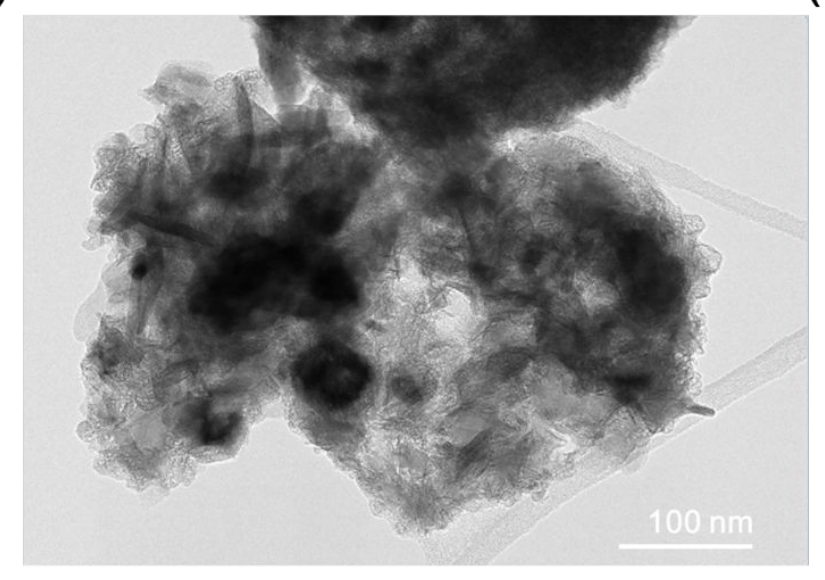

(b)

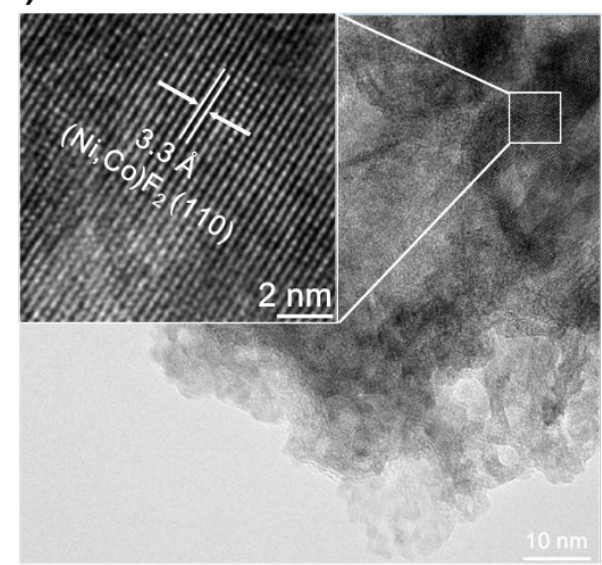

Figure S17. a) TEM and b) HR-TEM images of NCFO after prolonged OER in $1 \mathrm{M} \mathrm{KOH}$ solution. 

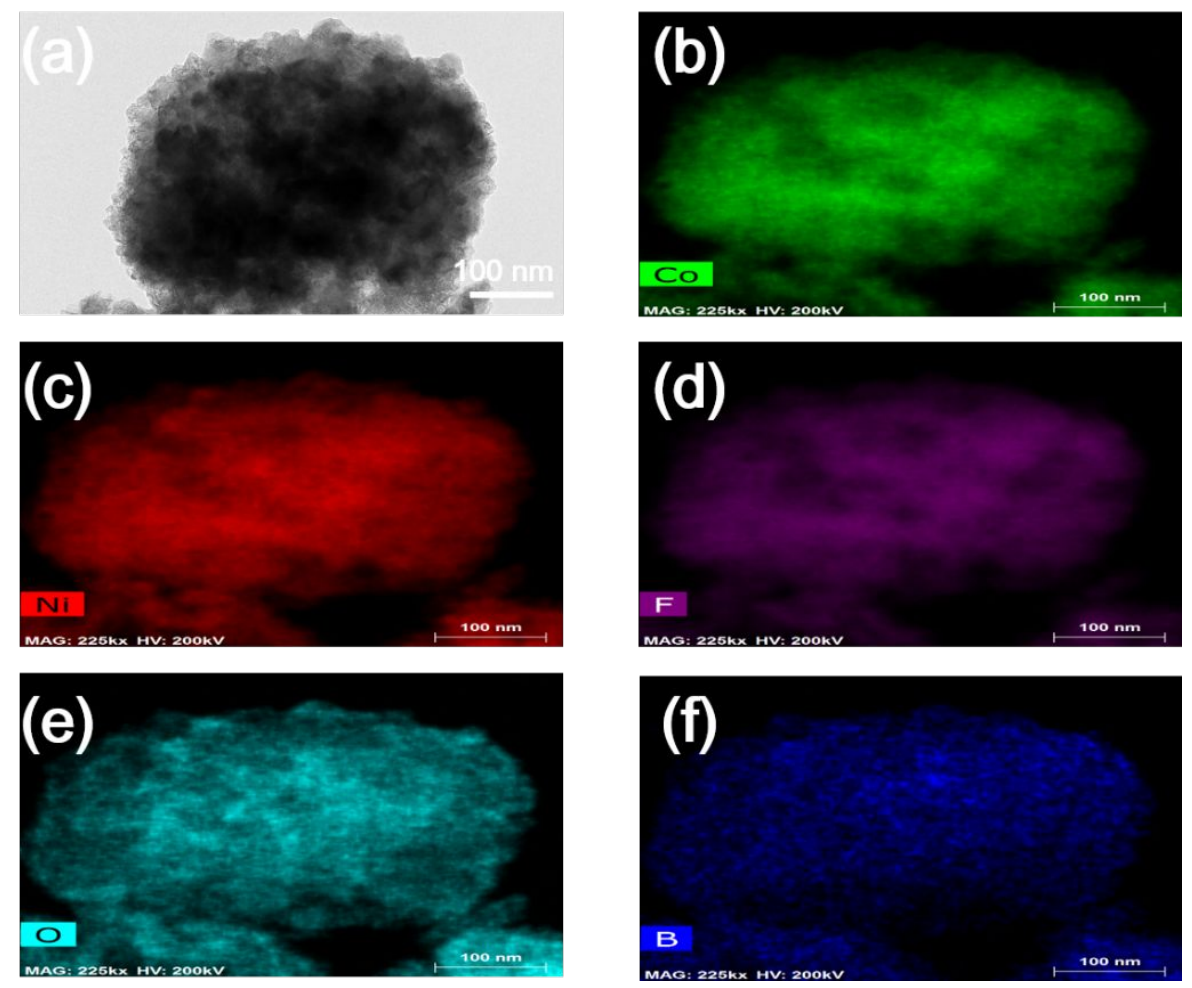

Figure S18. Elemental mapping images of a) post-OER NCFO for b) Co, c) Ni, d) F, e) O, and f) B. 

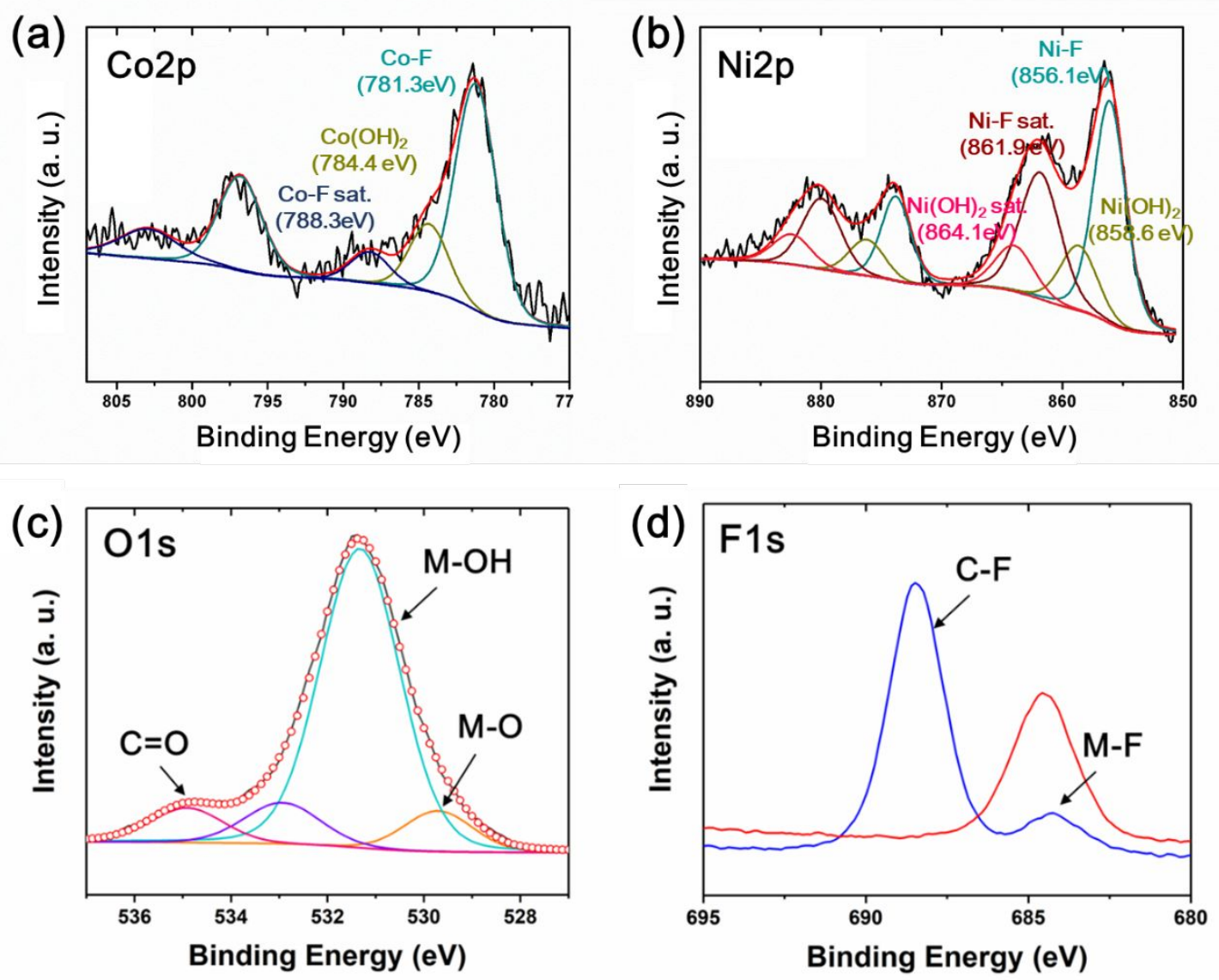

Figure S19. High-resolution XPS spectra for a) $\mathrm{Co}$, b) Ni, c) O, and d) F after prolonged OER in $1 \mathrm{M} \mathrm{KOH}$ solution. 
$\mathrm{OH}$
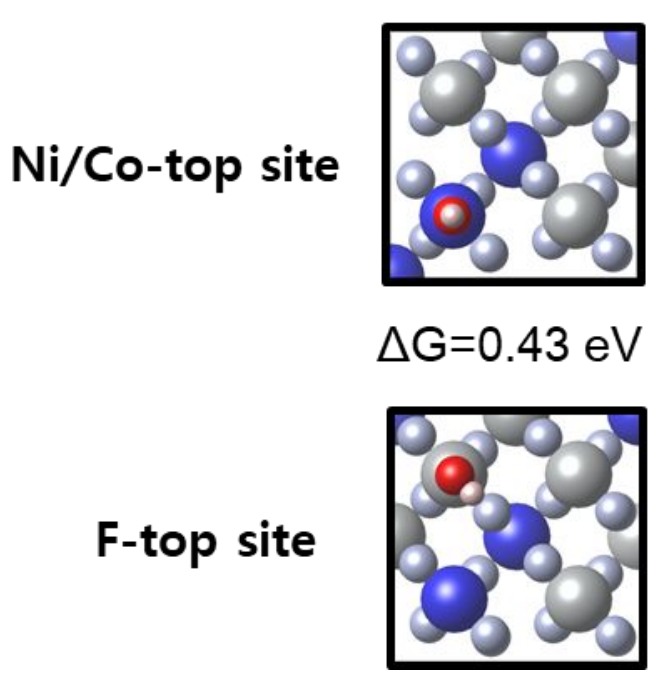

O

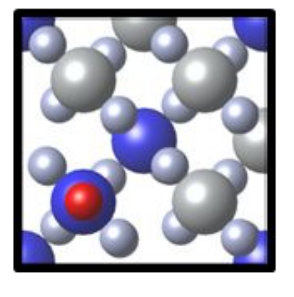

$\Delta \mathrm{G}=1.54 \mathrm{eV}$

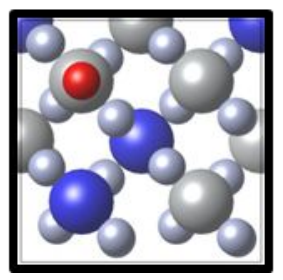

$\mathrm{OOH}$

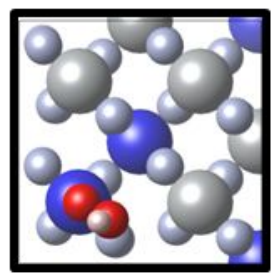

$\Delta \mathrm{G}=3.45 \mathrm{eV}$

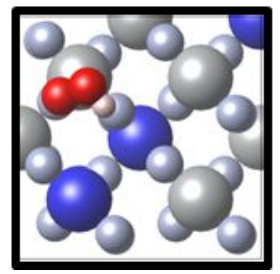

Figure S20. Preferred adsorption sites of Ni/Co-top and F top sites on nickel-cobalt-fluoride for $\mathrm{OH}, \mathrm{O}$, and $\mathrm{OOH}$ adsorptions. The blue, grey, silver, red, and white atoms represent $\mathrm{Co}$, $\mathrm{Ni}, \mathrm{F}, \mathrm{O}, \mathrm{H}$ atoms, respectively. 
Table S1. Comparison of OER catalytic activity of NCFO with that of other recently reported, transition metal-based catalysts (including nickel foam and carbon cloth supported) in alkaline media.

\begin{tabular}{|c|c|c|c|c|c|c|}
\hline Catalysts & Electrolyte & $\begin{array}{l}\text { Current } \\
\text { density } \\
\left(\mathrm{mA} \mathrm{cm}^{-2}\right) \\
\end{array}$ & $\begin{array}{c}\text { Overpo } \\
\text { tential } \\
(\mathrm{mV}) \\
\end{array}$ & $\begin{array}{c}\text { Tafel } \\
\text { slope } \\
\left.(\mathrm{mV} \mathrm{dec})^{-1}\right) \\
\end{array}$ & Substrate & References \\
\hline $\mathrm{NCFO}$ & $1 \mathrm{M} \mathrm{KOH}$ & 10 & 350 & 58 & $\mathrm{GC}^{*}$ & This work \\
\hline $\mathrm{NCFO} / \mathrm{NF}$ & $1 \mathrm{M} \mathrm{KOH}$ & 100 & 260 & - & $\mathrm{NF}^{* *}$ & This work \\
\hline $\mathrm{Co}_{2} \mathrm{~B}-500$ & $0.1 \mathrm{M} \mathrm{KOH}$ & 10 & 380 & 45 & $\mathrm{GC}$ & $\mathrm{S} 10$ \\
\hline $\mathrm{Ni}_{\mathrm{x}} \mathrm{B}-300$ & $1 \mathrm{M} \mathrm{KOH}$ & 10 & 380 & 89 & $\mathrm{GC}$ & $\mathrm{S} 11$ \\
\hline $\mathrm{Ni}-\mathrm{B} / \mathrm{NF}$ & $1 \mathrm{M} \mathrm{KOH}$ & 10 & 360 & 76 & $\mathrm{NF}$ & $\mathrm{S} 12$ \\
\hline Сo-3Mo-B & $1 \mathrm{M} \mathrm{KOH}$ & 10 & 320 & 155 & $\mathrm{GC}$ & S13 \\
\hline $\mathrm{Co}_{2} \mathrm{~B} / \mathrm{CoSe}_{2}$ & $1 \mathrm{M} \mathrm{KOH}$ & 10 & 320 & 56 & $\mathrm{GC}$ & $\mathrm{S} 14$ \\
\hline $\begin{array}{c}\text { Co-Ni-B@NF- } \\
500\end{array}$ & $1 \mathrm{M} \mathrm{KOH}$ & $\begin{array}{l}10 \\
100\end{array}$ & $\begin{array}{l}313 \\
470\end{array}$ & 120 & $\mathrm{NF}$ & S15 \\
\hline Ni-B $@$ NB & $1 \mathrm{M} \mathrm{KOH}$ & 10 & 302 & 52 & GC & S16 \\
\hline $\begin{array}{c}\mathrm{Co}_{9} \mathrm{~S}_{8} @ \mathrm{MoS}_{2} / \\
\mathrm{CNFs}\end{array}$ & $1 \mathrm{M} \mathrm{KOH}$ & 10 & 430 & 61 & $\mathrm{GC}$ & S17 \\
\hline $\begin{array}{c}\mathrm{NiCoS} / \mathrm{CC} \\
\mathrm{NSs}\end{array}$ & $1 \mathrm{M} \mathrm{KOH}$ & 10 & 330 & 109 & $\mathrm{CC}^{* * *}$ & $\mathrm{~S} 18$ \\
\hline $\begin{array}{l}\mathrm{NiCo}_{2} \mathrm{~S}_{4} \\
\mathrm{NA} / \mathrm{CC}\end{array}$ & $1 \mathrm{M} \mathrm{KOH}$ & 10 & 340 & 89 & $\mathrm{CC}$ & S19 \\
\hline $\mathrm{NiSe} / \mathrm{NF}$ & $1 \mathrm{M} \mathrm{KOH}$ & 10 & 400 & N/A & NF & $\mathrm{S} 20$ \\
\hline $\mathrm{CP} @ \mathrm{FeP}$ & $1 \mathrm{M} \mathrm{KOH}$ & 10 & 365 & 63 & $\mathrm{GC}$ & $\mathrm{S} 21$ \\
\hline $\mathrm{NiCoP} / \mathrm{NF}$ & $1 \mathrm{M} \mathrm{KOH}$ & 10 & 280 & 87 & NF & $\mathrm{S} 3$ \\
\hline Ni@Ni/C-400 & $1 \mathrm{M} \mathrm{KOH}$ & 100 & 450 & 54 & $\mathrm{GC}$ & $\mathrm{S} 22$ \\
\hline $\mathrm{NiNO} / \mathrm{CC}$ & $1 \mathrm{M} \mathrm{KOH}$ & 100 & 390 & 74 & $\mathrm{CC}$ & $\mathrm{S} 23$ \\
\hline
\end{tabular}




\begin{tabular}{ccccccc} 
NiCo2S2 & $1 \mathrm{M} \mathrm{KOH}$ & 100 & 370 & 40 & $\mathrm{NF}$ & $\mathrm{S} 24$ \\
$\mathrm{NW} / \mathrm{NF}$ & & & & & & \\
$\mathrm{Ni}_{2} \mathrm{P} @ \mathrm{NF}-6$ & $1 \mathrm{M} \mathrm{KOH}$ & 100 & 590 & 297 & $\mathrm{NF}$ & $\mathrm{S} 25$ \\
$\mathrm{Ni} @ \mathrm{Co}-\mathrm{Ni}-\mathrm{P}$ & $1 \mathrm{M} \mathrm{KOH}$ & 100 & 380 & 65 & $\mathrm{NF}$ & $\mathrm{S} 26$ \\
\hline *GC: glassy carbon, **NF: nickel foam, ***CC: carbon cloth & &
\end{tabular}


Table S2. Calculated Bader charges for each OER step on Co and F atoms. Positive and negative signs present the electron gain and electron loss, respectively.

\begin{tabular}{cccc}
\hline Atoms & $\mathrm{OH}$ & $\mathrm{O}$ & $\mathrm{OOH}$ \\
\hline Co1 & -0.18 & -0.12 & -0.15 \\
F1 & -0.0195 & 0.0399 & -0.0144 \\
F2 & -0.0195 & -0.0399 & -0.015 \\
F3 & 0.0046 & 0.0011 & 0.0096 \\
F4 & 0.0065 & -0.0003 & -0.0015 \\
\hline
\end{tabular}




\section{Reference for SI}

[[S1] Pintado, S.; Goberna-Ferron, S.; Escudero-Adan, E. C.; Galan-Mascaros, J. R., Fast and Persistent Electrocatalytic Water Oxidation by Co-Fe Prussian Blue Coordination Polymers. J Am Chem Soc 2013, 135, 13270-13273.

[S2] Wang, Z. C.; Liu, H. L.; Ge, R. X.; Ren, X.; Ren, J.; Yang, D. J.; Zhang, L. X.; Sun, X. P., Phosphorus-Doped $\mathrm{Co}_{3} \mathrm{O}_{4}$ Nanowire Array: A Highly Efficient Bifunctional Electrocatalyst for Overall Water Splitting. Acs Catal 2018, 8, 2236-2241.

[S3] Liang, H. F.; Gandi, A. N.; Anjum, D. H.; Wang, X. B.; Schwingenschlogl, U.; Alshareef, H. N., Plasma-Assisted Synthesis of NiCoP for Efficient Overall Water Splitting. Nano Lett 2016, 16, 7718-7725.

[S4] Perdew, J. P. ; Burke, K.; Ernzerhof, M., Generalized Gradient Approximation Made Simple. Phys Rev Lett 77 1996, 77, 3865.

[S5] Kresse, G.; Hafner, J., Ab Initio Molecular Dynamics for Liquid Metals. Phys Rev B: Condens Matter 1993, 47, 558.

[S6] Kresse, G.; Furtmüller, J., Efficiency of Ab-initio Total Energy Calculations for Metals and Semiconductors Using a Plane-wave Basis Set. Comput Mater Sci 1996, 6, 15.

[S7] Kresse, G.; Furtmüller, J., Efficient Iterative Schemes for Ab Initio Total-energy Calculations Using a Plane-wave Basis Set. Phys Rev B: Condens Matter 1996, 54, 11669.

[S8] Valdes, A.; Qu, Z. W.; Kroes, G. J.; Rossmeisl, J.; Norskov, J. K., Oxidation and photo-oxidation of water on $\mathrm{TiO}_{2}$ surface. J Phys Chem C 2008, 112, 9872-9879.

[S9] Atkins, P.; Paula, J. de, Atkins' physical chemistry, Oxford University Press, Oxford, 2006

[S10] Masa, J.; Weide, P.; Peeters, D.; Sinev, I.; Xia, W.; Sun, Z. Y.; Somsen, C.; Muhler, M.; Schuhmann, W., Amorphous Cobalt Boride $\left(\mathrm{Co}_{2} \mathrm{~B}\right)$ as a Highly Efficient Nonprecious Catalyst for Electrochemical Water Splitting: Oxygen and Hydrogen Evolution. Adv Energy Mater 2016, 6, 1502313.

[S11] Masa, J.; Sinev, I.; Mistry, H.; Ventosa, E.; de la Mata, M.; Arbiol, J.; Muhler, M.; Roldan Cuenya, B.; Schuhmann, W., Ultrathin High Surface Area Nickel Boride $\left(\mathrm{Ni}_{\mathrm{x}} \mathrm{B}\right)$ Nanosheets as Highly Efficient Electrocatalyst for Oxygen Evolution. Adv Energy Mater 2017, $7,1700381$.

[S12] Liang, Y. H.; Sun, X. P.; Asiri, A. M.; He, Y. Q., Amorphous Ni-B alloy nanoparticle film on Ni foam: rapid alternately dipping deposition for efficient overall water splitting. Nanotechnology 2016, 27, 0957-4484.

[S13] Gupta, S.; Patel, N.; Fernandes, R.; Hanchate, S.; Miotello, A.; Kothari, D. C., Co-MoB Nanoparticles as a non-precious and efficient Bifunctional Electrocatalyst for Hydrogen and Oxygen Evolution. Electrochim Acta 2017, 232, 64-71. 
[S14] Guo, Y. X.; Yao, Z. Y.; Shang, C. S.; Wang, E. K., Amorphous Co2B Grown on CoSe2 Nanosheets as a Hybrid Catalyst for Efficient Overall Water Splitting in Alkaline Medium. Acs Appl Mater Inter 2017, 9, 39312-39317.

[S15] Xu, N.; Cao, G. X.; Chen, Z. J.; Kang, Q.; Dai, H. B.; Wang, P., Cobalt nickel boride as an active electrocatalyst for water splitting. J Mater Chem A 2017, 5, 12379-12384.

[S16] Jiang, W. J.; Niu, S.; Tang, T.; Zhang, Q. H.; Liu, X. Z.; Zhang, Y.; Chen, Y. Y.; Li, J. H.; Gu, L.; Wan, L. J.; Hu, J. S., Crystallinity-Modulated Electrocatalytic Activity of a Nickel(II) Borate Thin Layer on $\mathrm{Ni}_{3} \mathrm{~B}$ for Efficient Water Oxidation. Angew Chem Int Edit 2017, 56, 6572-6577.

[S17] Zhu, H.; Zhang, J. F.; Yanzhang, R. P.; Du, M. L.; Wang, Q. F.; Gao, G. H.; Wu, J. D.; Wu, G. M.; Zhang, M.; Liu, B.; Yao, J. M.; Zhang, X. W., When Cubic Cobalt Sulfide Meets Layered Molybdenum Disulfide: A Core-Shell System Toward Synergetic Electrocatalytic Water Splitting. Adv Mater 2015, 27, 4752-4759.

[S18] Tang, C.; Pu, Z. H.; Liu, Q.; Asiri, A. M.; Luo, Y. L.; Sun, X. P., Ni $\mathrm{S}_{2}$ nanosheets array supported on $\mathrm{Ni}$ foam: A novel efficient three-dimensional hydrogen-evolving electrocatalyst in both neutral and basic solutions. Int J Hydrogen Energ 2015, 40, 4727-4732.

[S19] Liu, D. N.; Lu, Q.; Luo, Y. L.; Sun, X. P.; Asiri, A. M., NiCo2S4 nanowires array as an efficient bifunctional electrocatalyst for full water splitting with superior activity. Nanoscale 2015, 7, 15122-15126.

[S20] Tang, C.; Cheng, N. Y.; Pu, Z. H.; Xing, W.; Sun, X. P., NiSe Nanowire Film Supported on Nickel Foam: An Efficient and Stable 3D Bifunctional Electrode for Full Water Splitting. Angew Chem Int Edit 2015, 54, 9351-9355.

[S21] Xiong, D. H.; Wang, X. G.; Li, W.; Liu, L. F., Facile synthesis of iron phosphide nanorods for efficient and durable electrochemical oxygen evolution. Chem Commun 2016, $52,8711-8714$.

[S22] Sun, H.; Lian, Y. B.; Yang, C.; Xiong, L. K.; Qi, P. W.; Mu, Q. Q.; Zhao, X. H.; Guo, J.; Deng, Z.; Peng, Y., A hierarchical nickel-carbon structure templated by metal-organic frameworks for efficient overall water splitting. Energ Environ Sci 2018, 11, 2363-2371.

[S23] Huang, J. W.; Sun, Y. H.; Du, X. C.; Zhang, Y. D.; Wu, C. Y.; Yan, C. Y.; Yan, Y. C.; Zou, G. F.; Wu, W. Q.; Lu, R. F.; Li, Y. R.; Xiong, J., Cytomembrane-Structure-Inspired Active Ni-N-O Interface for Enhanced Oxygen Evolution Reaction. Adv Mater 2018, 30, 1803367.

[S24] Sivanantham, A.; Ganesan, P.; Shanmugam, S., Hierarchical $\mathrm{NiCo}_{2} \mathrm{~S}_{4}$ Nanowire Arrays Supported on Ni Foam: An Efficient and Durable Bifunctional Electrocatalyst for Oxygen and Hydrogen Evolution Reactions. Adv Funct Mater 2016, 26, 4661-4672.

[S25] Zheng, J. L.; Zhou, W.; Liu, T.; Liu, S. J.; Wang, C. B.; Guo, L., Homologous $\mathrm{NiO} / / \mathrm{Ni}_{2} \mathrm{P}$ nanoarrays grown on nickel foams: a well matched electrode pair with high stability 
in overall water splitting. Nanoscale 2017, 9, 4409-4418.

[S26] Li, W.; Gao, X. F.; Wang, X. G.; Xiong, D. H.; Huang, P. P.; Song, W. G.; Bao, X. Q.; Liu, L. F., From water reduction to oxidation: Janus Co-Ni-P nanowires as high-efficiency and ultrastable electrocatalysts for over $3000 \mathrm{~h}$ water splitting. J Power Sources 2016, 330, 156-166. 